\title{
Awareness and Practice of Prevention of Sexually Transmitted Diseases Among Demonstration Secondary School Students, University of Maiduguri, Borno State
}

\author{
Habu $\mathrm{H}^{1}$, Emmanuel OC ${ }^{2 *}$, Inuwa $\mathrm{A}^{1}$, Dathini $\mathrm{H}^{1}$, Maigari $\mathrm{B}^{1}$, Lona $\mathrm{N}^{1}$, Haruna $\mathrm{A}^{1}$ and Alih $\mathrm{FI}^{1}$ \\ ${ }^{1}$ Department of Nursing Science, College of Medical Sciences, University of Maiduguri, Maiduguri, Nigeria \\ ${ }^{2}$ School of Nursing, Mkar Gboko, Nigeria
}

\begin{abstract}
Sexually Transmitted Diseases or Infections are a major health problem across the globe and adolescence seems to be worst heat evidenced by increasing incidences of STDs among this age grades. This study assesses Awareness and Practice Preventive of Measures regarding (STDs) among Students of Demonstration Secondary School Maiduguri, Borno State. The study adopted survey method and used both primary and secondary data using questionnaire. One hundred twenty-one (121) respondents were selected using multi-stage sampling technique. Data were analyzed using descriptive statistics. The results showed that majority of the respondents $(71 \%)$ could identify HIV/AIDs as common examples of STIs followed by Gonorrhea with $55.5 \%$. However, respondents could not reasonably identify other forms of STIs evidenced by syphilis $(9.9 \%)$, Herpes Simplex $(5.8 \%)$ and Chlamydia $(5 \%)$. On the awareness of the mode of transmission STDs $(65 \%)$ agreed that STDs can be transmitted through sexual intercourse, sharing of underwear $(35 \%)$. Regarding prevention, $(72.7 \%)$ agreed that STIs are preventable. Majority of the respondents $(72 \%)$ also identified Health Education Lesson as their main source of information on STIs closely followed by Radio/Television and Friends with (44\%), (40\%) respectively. Although, this study revealed moderate awareness about respondents on common types of STDs, there is a need to do more by relevant authorities in order save our tomorrows' leaders from this clearly avoidable menace. Based on results of the study, the researchers recommended that Health Education lesson should be sustained. However, other forms of STIs should equally be considered in order to broaden the awareness respondents on STIs generally. Similarly, there is a need to intensify effort on preventive measures as well as negative use of social media.
\end{abstract}

Keywords: Assessment; Awareness; Practice; Prevention; Sexually transmitted diseases; Secondary school; Students

\section{Introduction}

Sexually Transmitted Diseases (STDs) formerly referred to as "Veneral disease" and now are referred to as Sexually Transmitted Infections (STIs) because an individual may be infected without necessarily developing the disease. STDs are transmitted from one person to another through intimate contact [1]. Studies have shown that, STDs are among the most common infectious diseases in the world with an estimated 333 million new cases of curable sexually transmitted diseases occur each year among adults [2]. Approximately one million people contract sexually transmitted infections every day and $50 \%$ of them are adolescents aged 15-24 years [3]. STDs include many different sexually transmittable infectious diseases such as Chlamydia, gonorrhea, genital herpes, Human Papilloma Virus (HPV), Human Immunodeficiency Virus (HIV), and syphilis [1]. An STD is transmitted through vaginal, oral and anal sexual contact as well as through blood products.

The incidence of STIs is fast increasing worldwide with the young, youth and adolescent placed at high risk. In the United State, there are estimated 15.3 million new cases of sexually transmitted infections each year and 3 million of which occur in people between the ages of 13-19 and one out of four sexually active teenagers reported a sexually transmitted infections every year [4]. Nearly two third (2/3) of all sexually transmitted infections occur in people younger than 25 years of age. In Nigeria, Adolescents otherwise known as young people are important segment of Nigerian society where it makes up over a third (31.6 percent) of Nigeria's large and growing population [5]. WHO [6] defines adolescence as persons between 10-24 years of age. It is a period of life from puberty to attainment of full maturity (adulthood) or growth, a time of being young when one's appearance is full of freshness, vigor and young spirit. Adolescents also share certain characteristics that distinguish them from other generation [7]. Such characteristic include, desire for independence, zealousness, radicalism, rebellions, curiosity, sexual risk behaviors, etc.

The level of sexual activity (pre-marital sex) among adolescents is high as well as the incidence of sexually transmitted infections. Therefore, the increased in the incidence of these infections and their scourge posed a greater challenge on the health care system as they contribute to increase in the morbidity and mortality rate among adolescent, exert a high physical and emotional toll on the afflicted individual as well as an economic burden on the individual, family, community and the health care system in general.

Adolescents are important segment of Nigerian society which makes up over a third (31.6 percent) of Nigeria's population [5]. Adolescents are generally defined as persons under various laws, conventions and culture, who are within the ages of 10-19 and 10-24 years old according to World Health Organization [6]. It is a period of life from puberty to attainment of full maturity (adult hood) or growth, a time of being young when one's appearance is full of freshness, vigor and young

${ }^{*}$ Corresponding author: Emmanuel OC, School of Nursing, Mkar Gboko, Nigeria, Tel: +07030578256, E-mail: emmanwaguy42@yahoo.com

Received June 27, 2018; Accepted July 02, 2018; Published July 09, 2018

Citation: Habu H, Emmanuel OC, Inuwa A, Dathini H, Maigari B, et al. (2018) Awareness and Practice of Prevention of Sexually Transmitted Diseases Among Demonstration Secondary School Students, University of Maiduguri, Borno State. J Health Educ Res Dev 6: 266. doi: 10.4172/2380-5439.1000266

Copyright: @ $2018 \mathrm{Habu} \mathrm{H}$, et al. This is an open-access article distributed under the terms of the Creative Commons Attribution License, which permits unrestricted use, distribution, and reproduction in any medium, provided the original author and source are credited. 
Citation: Habu H, Emmanuel OC, Inuwa A, Dathini H, Maigari B, et al. (2018) Awareness and Practice of Prevention of Sexually Transmitted Diseases Among Demonstration Secondary School Students, University of Maiduguri, Borno State. J Health Educ Res Dev 6: 266. doi: 10.4172/23805439.1000266

spirit. Adolescents also share certain characteristics that distinguish them from other generation. Such characteristic includes desire for independence, zealousness, radicalism, rebellions, curiosity, sexual risk behaviors, etc. It is both a period of opportunity as well as a time of vulnerability-a time of experimentation with new ideas and options and marked with vulnerability to health risk and those related to unsafe reproductive health outcomes.

Approximately one million people contract sexually transmitted infections every day and $50 \%$ of them are adolescents aged $15-24$ years [3]. The increase in the incidence of sexually transmitted infections among adolescents due to their sexually behaviors among other factors is now considered to be very important health challenges for adolescents [8]. Most importantly, these health problems often lead to psycho-social and economic problems, which include school dropout, stigmatization, isolation and probably depressive psychosis.

\section{Objectives of the study}

The general objective of this study was to assess the awareness and practice of prevention of Sexually Transmitted Diseases among Demonstration Secondary School Students, University of Maiduguri, Borno State.

The specific objectives were to:

- Assess the awareness of the Students on Sexually Transmitted Infections;

- Ascertain preventive measures employed by the students towards Sexually Transmitted Diseases;

- Identify their sources of information on Sexually Transmitted Diseases; and

- Identify factors influencing sexual behavior among the students.

\section{Study hypotheses}

$\mathrm{Ho}_{1}$ There is no significant difference between gender of the respondents and factors influencing sexual behavior,

$\mathrm{Ho}_{2}$ There is no significant difference between level of education of the respondents and knowledge regarding STDs.

\section{Related Work}

Cross-sectional surveys conducted among school-attending adolescents aged 13 to 20 years on Awareness and knowledge of Sexually Transmitted Diseases (STDs) among school-going adolescents in Europe: a systematic review of published literature by SamkangeZeeb et al. [9] using a total of 15 studies, revealed that generally, awareness and knowledge varied among the adolescents depending on gender. Six STDs were focused on in the studies included in the review, with awareness and knowledge being assessed in depth mainly for HIV/AIDS and HPV, and to some extent for chlamydia. For syphilis, gonorrhea and herpes only awareness was assessed. Awareness was generally high for HIV/AIDS (above 90\%) and low for HPV (range 5.4\%-66\%). Despite knowing that use of condoms helps protect against contracting an STD, some adolescents still regard condoms primarily as an interim method of contraception before using the pill.

Study by Mudassir et al. [10] on Awareness of School Students on Sexually Transmitted Infections (STIs) and their Sexual Behavior: A Cross-sectional Study Conducted in Pulau Pinang, Malaysia showed that sexual experience related significantly with gender, race, and education level. Approximately $12.6 \%$ claimed to have sexual experience of which $75.7 \%$ had their sexual debut at $15-19$ years and $38.2 \%$ were having more than 3 partners. Sexual experience was found to be significantly associated with gender $(\mathrm{p}=0.003)$, ethnicity $(\mathrm{p}=0.001)$ and education level $(\mathrm{p}=0.030)$. However, multiple partner behavior was significantly associated only with gender $(\mathrm{p}=0.010)$. Mean knowledge score was $11.60 \pm 8.781$ and knowledge level was significantly associated with religion $(\mathrm{p}=0.005)$ education level $(\mathrm{p}=0.000)$, course stream $(\mathrm{p}=0.000)$, socioeconomic class $(\mathrm{p}=0.000)$ and sexual experience $(\mathrm{p}=0.022)$.

Amu et al. [11] carried out study on Awareness and Knowledge of Sexually Transmitted Infections among Secondary School Adolescents in Ado Ekiti, South Western Nigeria. The finding showed Four hundred and ninety-nine (92.4\%) respondents had heard about sexually transmitted infections before, the three most important sources of information being electronic media (68.7\%); teachers (68.1\%); and print media (44.9\%). Eighty percent of the respondents knew only one STI and the two most commonly mentioned ones were HIV/AIDS (78.0\%) and gonorrhea (23.0\%). More than $75 \%$ of the respondents knew the modes of transmission of STIs while some of them equally had misconceptions. The most important symptoms mentioned were weight loss (77.4\%), painful micturition (68.9\%), and genital ulcer $(54.1 \%)$. On the whole, only $6.9 \%$ of the respondents had good knowledge of STIs; the rest had fair and poor knowledge [12]. On Knowledge and Awareness of Sexually Transmitted Diseases among Male University Students in Taif, Saudi Arabia showed that among those who have knowledge about STDS, 35\% had their knowledge from the friends while $29.9 \%$ and $27.7 \%$ had their knowledge from internet and television respectively. Less than half of them (47\%) knew that condom could not protect $100 \%$ from STDs while slightly more than half of them (54.3\%) knew that oral contraceptive use doesn't decrease the risk of STDs among women. Only 38\% knew that there is no available vaccination against STDs. Slightly more than one-third of the participants (36.8\%) knew that STDs infected mother could transmit a sexual disease to her newborn during labor. the great majority of students $(98.5 \%)$ are aware of HIV/AIDS as a STD while only $37.3 \%$ were aware that Chlamydia is a STD. Married status, high level of paternal education and having information from friends or internet were associated with better STDs knowledge.

Study by Dangui et al. [13] showed that of 3425 website visitors, 1030 university students completed the survey, of which $80 \%$ were between 20 and 25 years of age, $76 \%$ considered premarital sex acceptable, $21 \%$ had had sexual intercourse, and $45 \%$ of sexually active students had engaged in oral sex, anal intercourse, or sex with strangers. Students had limited knowledge and awareness about common STIs, symptoms, and complications. Three percent of the sexually active students reported having had STIs and another $8 \%$ were not sure whether they had or not. Most students had misconceptions about transmission and prevention of STIs. The internet was the main information resource for $76 \%$ of students.

Florence [14] carried out study on Assessing knowledge and awareness of sexually transmitted infections among school-going adolescents. Fifteen studies focusing on six STIs were included in the systematic review. Awareness and knowledge were assessed in depth mainly for HIV/AIDS and HPV and to some extent for chlamydia. A total of 1148 pupils (31\% with a migrant background and $55 \%$ girls) participated in the school-based survey. In the studies included in the review as well as in the school-based survey, HIV/AIDS was the infection most pupils had heard of. In the latter, slightly more than half of the pupils correctly answered at least 2 of the four items used 
Citation: Habu H, Emmanuel OC, Inuwa A, Dathini H, Maigari B, et al. (2018) Awareness and Practice of Prevention of Sexually Transmitted Diseases Among Demonstration Secondary School Students, University of Maiduguri, Borno State. J Health Educ Res Dev 6: 266. doi: 10.4172/23805439.1000266

Page 3 of 6

to assess knowledge of sexually transmitted infections. There was a clear difference in knowledge and awareness according to age, sex and migrant background, with better knowledge and awareness scores for girls, older pupils and those without a migrant background. The most common sources of information on sexuality and sexually transmitted infections mentioned by the pupils were the school (biology lessons) and the mother. $12 \%$ of the participating girls reported having been vaccinated against human papillomavirus, while $57 \%$ reported not knowing whether or not they were vaccinated. Regarding the rating of risk of peers to get infected with HPV or chlamydia, the majority of pupils responded with 'don't know'. Those who did do the rating generally rated the risk for peers to get infected with HIV as being higher than that for chlamydia or HPV. Those reporting ever having sex also reported their own risk of getting infected with HIV to be higher than for HPV or chlamydia.

\section{Methods}

\section{Study design}

Cross-sectional descriptive survey was used to assess the awareness and practice of prevention of sexually transmitted diseases among demonstration secondary school students, university of Maiduguri, Borno State.

\section{Population of the study}

The population of study comprised all the 297 senior students in the study area: Demonstration Secondary school, University of Maiduguri, Borno State.

\section{Sample size and sampling technique}

The total population of the students in the senior class is 297. To get the sample size, Yamane formula was used to determine the study sample size as follows:

The formula:

$$
n=\frac{N}{1+N\left(e^{2}\right)}
$$

Description of the formula:

$\mathrm{n}=$ require sample size,

$\mathrm{N}=$ total population of the study,

$\mathrm{e}=$ margin of error at $5 \%$ (standard value of 0.05 ),

Substituting the formula therefore:

$$
\begin{aligned}
& n=\frac{297}{1-297\left(0.05^{2}\right)} \\
& n=\frac{297}{1+297(0.0025)} \\
& n=170 \\
& n=170
\end{aligned}
$$

After obtaining the sample size, a stratified sampling technique was used to select 170 respondents from the target population. Formally, senior classes comprises of SS1, SS2 and SS3 where each of the class was adopted as stratum for the study.

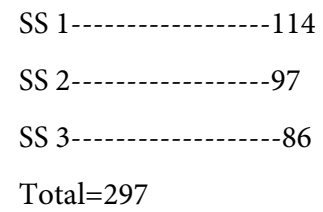

A simple random sampling technique was then used to select the 170 from the stratum proportionately (65, 56 and 49 respectively). However, SSIII could not be accessed because they were writing final exams as of the time of administering the questionnaire. Therefore, respondents were selected from SSI and SSII. 121 respondents were used for the study.

\section{Instrument of data collection}

Questionnaire (121) was designed to obtain the relevant data. The questionnaire contains 22 questions in line the specific objectives of the study. All the (121) research questionnaires were distributed to the randomly selected respondents and were retrieved immediately after filling the required information. The questionnaire was divided into the following segments:

Section A: Socio-demographic variables.

Section B: Awareness of students on STIs.

Section C: Preventive measures employed by the students on STIs.

Section D: Students' sources of information on STIs.

Section E: Factors influencing sexual behavior among students.

\section{Method of data analysis}

Data collected were presented and analyzed using descriptive statistics (frequency counts and percentages) and the hypotheses were tested using Chi-square.

\section{Data presentation and analysis}

A total of 121 questionnaires were distributed to the respondents and same was retrieved. The data presentation and analysis of the retrieved data was done through frequency distribution table with percentages. The formulated hypotheses were tested using chi-square and major findings were also discussed under this chapter.

On the Socio-demographic characteristics of the respondents, Table 1 shows that majority of the respondents 86 (61.2\%) were between the ages of 15-17 years, 27(22.3\%) of the respondents were between the ages of 18-20 years, 16(13.1\%) were between the ages of 12-14 years, $2(1.7 \%)$ were between the ages of 9-11 years of age and 2(1.7\%) were 21 and above. On sex distribution 64(52.9\%) were male while were $(47.1 \%)$ are female (Tables 2 and 3 ). The study equally revealed that $86(71.1 \%)$ were Muslim while $35(28.9 \%)$ were Christian. In terms class distribution, 65(53.7\%) of the respondents were in SS I, 56(46.3\%) were in SS II, 0\% was recorded in SS III (because they were not available during the period of the data collection). Marital status shows that $102(84.3 \%)$ of the respondents were single, $17(14.0 \%)$ are married and 2(1.7\%) divorced.

On the respondents awareness on STIs, Table 4 shows that majority of the respondents $84(69.4 \%)$ have heard about STIs before, $37(30.6 \%)$ have never heard about it. $80(66.1 \%)$ of the respondents claimed to have been educated or enlighten specifically of STIs while 41(33.9\%) claimed otherwise. 93(76.9\%) affirmed that they were aware of the existence of STIs among adolescents in Nigeria while 28(23.1\%) claimed they don't know. 
Citation: Habu H, Emmanuel OC, Inuwa A, Dathini H, Maigari B, et al. (2018) Awareness and Practice of Prevention of Sexually Transmitted Diseases Among Demonstration Secondary School Students, University of Maiduguri, Borno State. J Health Educ Res Dev 6: 266. doi: 10.4172/23805439.1000266

Page 4 of 6

On the respondents awareness about the diseases that are classified as STIs, Table 3 showed that, majority of the respondents $86(71.0 \%)$ identified HIV/AIDs as STIs, 67(55.5\%) could identified gonorrhea as STIs, 12(9.9\%) identified Syphilis as STIs, $8(6.6 \%)$ identified human papilloma virus as STIs, 7(5.8\%) identified Herpes simplex, 2(2.5\%) identified typhoid, 2(1.7\%) said Tuberculosis is an example STIs and 2(1.7\%) identified Chlamydia. 1(0.8\%) each for pneumonia and Trichomoniasis were identified as STIs. Also none of the respondents mentioned others disease as STIs other than above mentioned.

On the respondents knowledge on the mode of transmission, Table 4 showed that majority the respondents $79(65 \%)$ agreed sexual intercourse to be a means by which sexually transmitted infections transmitted, $42(34.7 \%)$ agreed sharing of sharp object as easy means contacting STIs while 37(30.8\%) agreed sharing of underwear and same number agreed that it could be transmitted through blood contact, 5(4.1\%) mentioned hugging while 4(3.3) shaking hand as a mode of transmission. Others, 14(11.6\%) mentioned blood transfusion and kissing with an infected person who have sore in his mouth.

On the respondent knowledge on the prevention, Table 5 shows that, majority of the respondents $88(72.7 \%)$ know that STIs can be prevented while $33(27.3 \%)$ said otherwise. $71(58.7 \%)$ have agreed used of condom during sex can prevent contracting STIs while 50 (41.3\%) did not agree that condom can prevent STIs. Also majority of the respondents $84(69.4 \%)$ know that abstinence is the best way of prevention while $37(30.6 \%)$ said otherwise. Regarding sexual partner(s), 80(66.1\%) know that, avoiding multiple sexual partners can help in preventing STIs while $41(33.9 \%)$ disagreed. On whether the respondent had ever had sex, 44(36.4\%) acknowledge that they had

\begin{tabular}{|c|c|c|}
\hline Variable & Frequency & Percentage (\%) \\
\hline \multicolumn{3}{|c|}{ Age } \\
\hline 09-Nov & 2 & 1.7 \\
\hline Dec-14 & 16 & 13.1 \\
\hline $15-17$ & 74 & 61.2 \\
\hline $18-20$ & 27 & 22.3 \\
\hline 21-above & 2 & 1.7 \\
\hline Total & 121 & 100 \\
\hline \multicolumn{3}{|c|}{ Sex } \\
\hline Male & 64 & 52.9 \\
\hline Female & 57 & 47.1 \\
\hline Total & 121 & 100 \\
\hline Religion & M & \\
\hline Islam & 86 & 71.1 \\
\hline Christianly & 35 & 28.9 \\
\hline Others & 0 & 0 \\
\hline Total & 121 & 100 \\
\hline \multicolumn{3}{|c|}{ Educational level } \\
\hline SS I & 65 & 53.7 \\
\hline SS II & 56 & 46.3 \\
\hline SS III & 0 & 0 \\
\hline Total & 121 & 100 \\
\hline \multicolumn{3}{|c|}{ Marital status } \\
\hline Single & 102 & 84.3 \\
\hline Married & 17 & 14 \\
\hline Divorced & 2 & 1.7 \\
\hline Widowed & 0 & 0 \\
\hline Total & 121 & 100 \\
\hline
\end{tabular}

Table 1: Socio Demographic data of the respondents.

\begin{tabular}{|c|c|c|c|}
\hline Variable & \multicolumn{2}{|c|}{ Responses (frequency) } & Total \\
\hline \multirow{2}{*}{ Have you ever heard of STIs } & Yes (\%) & No (\%) & 121 (100\%) \\
\cline { 2 - 4 } & 8469.4 & 3730.6 & 121 \\
\hline $\begin{array}{c}\text { Have ever been educated or enlighten } \\
\text { specifically on STIs? }\end{array}$ & 8066.1 & 4133.9 & $-100 \%$ \\
\hline $\begin{array}{c}\text { Do you know STIs exist among } \\
\text { adolescents in Nigeria }\end{array}$ & 9379.9 & 2823.1 & -121 \\
\hline
\end{tabular}

Table 2: Respondents level of awareness on STIs.

\begin{tabular}{|c|c|c|}
\hline Variable & Frequency & Percentage (\%) \\
\hline STIs include & & \\
\hline HIVIAIDs & 86 & 71.0 \\
\hline Gonorrhea & 67 & 55.5 \\
\hline Syphilis & 12 & 9.9 \\
\hline Typhoid & 3 & 2.5 \\
\hline Tuberculosis & 2 & 1.7 \\
\hline Human papiloma virus & 8 & 6.6 \\
\hline Herpes simplex & 7 & 5.8 \\
\hline Pneumonia & 1 & 0.8 \\
\hline Chlamydia & 6 & 5.0 \\
\hline Trichomoniasis & 1 & 0.8 \\
\hline Others & 00 & 00 \\
\hline
\end{tabular}

Table 3: Respondents awareness about the diseases classified as STIs.

\begin{tabular}{|c|c|c|}
\hline Variable & Frequency & Percentage (\%) \\
\hline STls can be transmitted by & & \\
\hline Sexual intercourse & 79 & 65.3 \\
\hline Sharing underwear & 42 & 34.7 \\
\hline Sharing sharp object & 37 & 30.8 \\
\hline Through contact with blood & 37 & 30.8 \\
\hline Hugging & 5 & 4.1 \\
\hline Shaking hands & 4 & 3.3 \\
\hline Others & 14 & 11.6 \\
\hline
\end{tabular}

Table 4: Respondents awareness on the mode of transmission of STIs.

sex before, however, majority 77(63.6\%) said they never had sex before. 86(71.15) indicate that, they can seek Health Care when they noticed any unusual development in the reproductive organs while $35(28.9 \%)$ said they will seek for Health Care. 41(38.9\%) said they use herbs to avoid as well as treatment measure.

Table 6 shows that majority of the respondents 87 (72\%) acknowledged Health Education Lesson as their source of information on STIs while 53 (44\%) indicated friends as their source of information on STIs. Radio/Television 48 (40\%), 10 (8.3\%) said they read about it on their own and $2(1.7 \%)$ for others.

Table 7 shows that $46(76 \%)$ and $38(66.6 \%)$ of male and female respondents respectively identified Peer Pressure as a likely factor that may influence their sexual behavior. Drug Abuse 43 (67.2\%) for male and $29(50 \%)$ for female, Social Media 40 (62.5\%) and $44(77.2 \%)$ for male and female respectively. On the influence parents, 39 (61\%) for male while $50(87 \%)$ for female. Regarding the influence of the school on the sexual behavior of the respondents, 45 (70\%) and 43 (75\%) for both sexes respectively (Tables 8 and 9).

The calculated $x^{2}$ is 9.3498 while the tabulated value of $x^{2} 11.0705$, $\mathrm{df}=5, \mathrm{p}=0.050$. Since the calculated value of $\mathrm{x}^{2}$ is less than table value of $\mathrm{x}^{2}$, the null hypothesis is accepted. By accepting the null hypothesis, we therefore, conclude that there is no significant relationship between gender and factors influencing sexual behavior among adolescence. 
Citation: Habu H, Emmanuel OC, Inuwa A, Dathini H, Maigari B, et al. (2018) Awareness and Practice of Prevention of Sexually Transmitted Diseases Among Demonstration Secondary School Students, University of Maiduguri, Borno State. J Health Educ Res Dev 6: 266. doi: 10.4172/23805439.1000266

Page 5 of 6

\begin{tabular}{|c|c|c|c|}
\hline Variable & Respo & uency) & Total \\
\hline \multirow{2}{*}{ Do you know STIs can be prevented } & Yes $(\%)$ & No $(\%)$ & \multirow{2}{*}{$121(100 \%)$} \\
\hline & 8872.7 & 3327.3 & \\
\hline Do you know use of condom during sex can avoid contracting STIs & 7158.7 & 5041.3 & $121(100 \%)$ \\
\hline Do you know abstinence is best way to avoid contracting STls & 8469.4 & 3730.6 & $121(100 \%)$ \\
\hline Do you know avoiding multiple sexual partners can prevent contracting STIs & 8066.1 & 4133.9 & $121(100 \%)$ \\
\hline Have you had sex in your life & 4436.4 & 7763.6 & $121(100 \%)$ \\
\hline Do you seek for health care when you notice a problem with your reproductive organs? & 8671.1 & 3528.9 & $121(100 \%)$ \\
\hline Do you use herbs to avoid contracting or treating STIs? & 4138.9 & 8066.1 & $121(100 \%)$ \\
\hline
\end{tabular}

Table 5: Respondents awareness on the prevention and mode of practice of STls.

\begin{tabular}{|c|c|c|}
\hline Variable & Frequency & Percentage (\%) \\
\hline How did you come know about STIs? & & \\
\hline Radio/Television & 48 & 39.7 \\
\hline Health Education Lesson & 87 & 71.9 \\
\hline Parents & 42 & 34.7 \\
\hline Friends & 53 & 43.8 \\
\hline I read about it on my own & 10 & 8.3 \\
\hline Newspaper & 2 & 1.7 \\
\hline
\end{tabular}

Table 6: Students sources of information on STIs.

\begin{tabular}{|c|c|c|c|}
\hline Variable & \multicolumn{3}{|c|}{ Gender } \\
\hline $\begin{array}{c}\text { Which of the following is likely to } \\
\text { influence your sexual behavior? }\end{array}$ & Male $(\mathrm{n}=64)$ & $\begin{array}{c}\text { Female } \\
(\mathrm{n}=57)\end{array}$ & Total \\
\hline Peer Pressure & $46(76 \%)$ & $38(66.7 \%)$ & 84 \\
\hline Drug Abuse & $43(67.2 \%)$ & $29(50.9 \%)$ & 72 \\
\hline Social Media & $40(62.5 \%)$ & $44(77.2 \%)$ & 84 \\
\hline Parents & $39(61.0 \%)$ & $50(87.7 \%)$ & 89 \\
\hline School & $45(70.3 \%)$ & $43(75.4)$ & 88 \\
\hline Newspaper & $17(26.6)$ & $6(10.5 \%)$ & 23 \\
\hline
\end{tabular}

Table 7: Factors likely to influence the sexual behavior of the Respondents.

\begin{tabular}{|c|c|c|c|}
\hline \multicolumn{1}{|c|}{ Variable } & \multicolumn{3}{|c|}{ Gender } \\
\hline $\begin{array}{c}\text { Which of the following is likely to } \\
\text { influence your sexual behavior? }\end{array}$ & Male & Female & Total \\
\hline Peer Pressure & $46(43.91)$ & $38(40.1)$ & 84 \\
\hline Drug Abuse & $43(37.64)$ & $29(34.36)$ & 72 \\
\hline Social Media & $40(43.91)$ & $44(40.1)$ & 84 \\
\hline Parents/peers & $39(46.52)$ & $50(42.48)$ & 89 \\
\hline School & $45(46)$ & $43(42)$ & 88 \\
\hline Others & $17(12.02)$ & $6(11)$ & 23 \\
\hline Total & $\mathbf{2 3 0}$ & $\mathbf{2 1 0}$ & 440 \\
\hline
\end{tabular}

Table 8: $\mathrm{Ho}_{1}$ Relationship between gender and factors influencing sexual behaviour among adolescence.

\begin{tabular}{|c|c|c|c|}
\hline Variable & \multicolumn{3}{|c|}{ Level of Education } \\
\hline Have ever been educated or & \multirow{2}{*}{ SS I $(\mathrm{n}=65)$} & SS II $(\mathrm{n}=56)$ & Total \\
\hline Enlighten specifically on STIs? & $35(42.98)$ & $45(37.02)$ & $\mathbf{8 0}$ \\
\hline Yes & $30(22.02)$ & $11(18.98)$ & $\mathbf{4 1}$ \\
\hline No & $\mathbf{6 5}$ & $\mathbf{5 6}$ & $\mathbf{1 2 1}$ \\
\hline Total &
\end{tabular}

Table 9: $\mathrm{Ho}_{2}$ Relationship between level education and awareness of STIs.

The calculated $\mathrm{x}^{2}$ is 9.4488 while the tabulated value of $\mathrm{x}^{2} 3.8415$, $\mathrm{df}=1, \mathrm{p}=0.050$. Since the calculated value of $\mathrm{x}^{2}$ is greater than table value of $\mathrm{x}^{2}$, the null hypothesis is rejected. By rejecting the null hypothesis, we therefore, conclude that there is significant relationship between awareness of STIs and level of education among adolescence.

\section{Discussion of Findings}

In this study, the Awareness and Practice of Prevention of Sexually Transmitted Infections among adolescents in Demonstration Secondary School, University Maiduguri was conducted through the use of a questionnaire. The findings of the study were discussed according to the research question designed to achieve the objective of the study. Thus:

The result of the study indicates that majority (71\%) of respondents could identify HIV/AIDs as common examples of STIs followed by Gonorrhea with $55.5 \%$. This shows that there is high level awareness. However; respondents could not reasonably identify other forms of STIs, maybe because those ones are not common to them. This finding is in agreement with Amu et al. [11] who reported in similar study that majority (92.4\%) of the students (i.e., respondents) were aware of STIs. Also, Samkange-Zeeb et al. [9], Mudassir et al. [10] in similar study, reported low level of awareness and knowledge for STIs with the exception of HIV/AIDs.

On the mode of transmission, significant percentage of the respondents had also demonstrated moderate awareness on the mode of transmission of STIs: $65.3 \%$ identified sexual intercourse, $34.7 \%$ sharing of under wear and $30.8 \%$ each for sharing of sharp object and blood contact. This is also closely related with Hafsat et al. [15] who in a similar study reported that only $55 \%$ knew at least two mode of transmission for HIV/AIDs. The finding is also similar to that of Basim [12] whose study showed less than half of the respondents $(47 \%)$ knew that condom could not protect $100 \%$ from STDs while slightly more than half of them (54.3\%) knew that oral contraceptive use doesn't decrease the risk of STDs among women. Only $38 \%$ knew that there is no available vaccination against STDs. Similar study by Dangui et al. [13] showed that most students had misconceptions about transmission and prevention of STIs. The internet was the main information resource for $76 \%$ of students.

The result of the study indicates that majority of the respondents (72.7\%) agreed that STIs are preventable. However, the most revealing aspect of this study was that $36.4 \%$ acknowledged they had sex before. This implies reasonable sexual activities among the adolescence and by extension high STIs vulnerability risk. This assertion is supported by surveys conducted on sexual behaviors of Nigerian Adolescents Nigeria Demographic and Health Survey [16] which showed that Nigerian adolescent (15-19) almost half of the females (46.2\%) and about a quarter of males (22.1\%) have engaged in sexual intercourse. This is also, in line with Andersson et al. [11] who reported that in Nigeria, the level of sexual activity (pre-marital sex) among adolescents is high as well as the incidence of STIs.

On a whole, $58-69 \%$ had demonstrated good awareness on the preventive measures of STIs on parameters like use condom, avoidance of multiple sex partners and seeking for medical attention. This finding 
Citation: Habu H, Emmanuel OC, Inuwa A, Dathini H, Maigari B, et al. (2018) Awareness and Practice of Prevention of Sexually Transmitted Diseases Among Demonstration Secondary School Students, University of Maiduguri, Borno State. J Health Educ Res Dev 6: 266. doi: 10.4172/23805439.1000266

Page 6 of 6

is related with Andersson et al. [17] who carried out a similar studied to test the knowledge about mode of transmission and prevention of STIs among young women $16-32$ years of age, the result showed varying awareness levels of between $44 \%-64 \%$.

The findings of the study also show that, majority of the respondents 87(72\%) identified Health Education Lesson as their main source of information on STIs. This implies that Health Education lesson is an effective channel to creating awareness in the Demonstration Secondary School, University of Maiduguri. The role Radio/Television and Friends with 53(44\%), 48(40\%) respectively, were also prominent sources of information on STIs to the respondents. This is also in agreement with, Amu et al. [11] who in similar study identified electronic media $68.7 \%$, Teachers $68.1 \%$ and print media $44.9 \%$ as other sources of information for adolescence regarding STIs.

The result shows that $46(76 \%)$ and $38(66.6 \%)$ of male and female respondents respectively identified Peer Pressure as a likely factor that may influence their sexual behavior. Drug Abuse 43(67.2\%) for male and $29(50 \%)$ for female, Social Media 40(62.5\%) and 44(77.2\%) for male and female respectively. On the influence parents, 39(61\%) for male while 50(87\%) for female. Regarding, the influence of the school on the sexual behavior of the respondents, $45(70 \%)$ and $43(75 \%)$ for both sexes respectively.

\section{Summary}

Awareness and practice of prevention of sexually transmitted infections among adolescents in Demonstration Secondary University of Maiduguri. 121 students (respondents) were selected using simple random sampling technique where questionnaires were used to collect the relevant data for the study. Major findings of the study revealed that $75 \%$ of the students were aware of STIs and knew HIV/AIDs and gonorrhea as the common type of STIs. However; respondents could not reasonably identify other forms of STIs evidenced by syphilis (9.9\%), Herpes Simplex (5.8\%) and Chlamydia (5\%). On the awareness of the mode of transmission STDs (65\%) agreed that STDs can be transmitted through sexual intercourse, sharing of underwear (35\%). Regarding prevention, (72.7\%) agreed that STIs are preventable. Majority of the respondents (72\%) also identified Health Education Lesson as their main source of information on STIs closely followed by Radio/Television and Friends/peers with (44\%), (40\%) respectively.

\section{Conclusion}

The study Awareness and Practice of Prevention of Sexually Transmitted Infections among adolescents in Demonstration Secondary School, University Maiduguri was conducted through the use of a questionnaire. The findings of the study revealed moderate awareness among the respondents. However, there is a need to improve on the existing awareness platforms in order to broaden the respondent's awareness level on most of the STIs. Health Education lesson should be sustained as it happened to be one of the major sources of information on STIs. However, other forms of STIs should equally be considered in order to broaden the awareness respondents on STIs generally. Similarly, there is a need to intensify effort on preventive measures as well as negative use of social media.

\section{Recommendations}

Based on the findings of the study the researcher recommends the following:

- The findings of study revealed Health Education lesson as an effective channel to creating awareness about STIs. Therefore, there is a need for Health Education lesson in the school to be sustained. However, other forms of STIs should equally be considered in order to broaden the awareness of STIs generally.

- Although, the findings of the study showed moderate awareness and practice of preventive measures regarding STIs, there is a need to intensify effort on preventive measures by the school authority.

- STIs club as it exists in some secondary school should be encouraged to serve as an additional source of information on STIs.

- Drug abuse and negative use of social media should discourage through intensive awareness campaign.

\section{References}

1. Center for Disease Control (CDC) (2010) Sexually transmitted diseases.

2. WHO (2011) Sexually transmitted infections.

3. Lazarus JV, Sihvonen-Riemenschneider H, Laukamm-Josten U, Wong F Liljestrand J (2010) Systematic review of interventions to prevent the spread of sexually transmitted infections, including HIV, among young people in Europe. Croatian Medical Journal 51: 74-84.

4. Chinsembu KC, Kasanda CD, Shimwooshili-Shaimemanya CN (2011) Impact of HIVIAIDS on Secondary School Science Teachers and Learners in Namibia. Journal of Public Health and Epidemiology 11: 540-549.

5. WHO (2012) Sexually transmitted infections among adolescents. Retrieved on September 14th, 2014.

6. WHO (2001) Global Consultation of Friendly Health Services A Consensus Statement. Department of Adolescent and Child Health and Development Geneva, 7-12 March 2001. Retrieved on September 14th, 2014.

7. Mercy OF, Peter AS (2014) Risky Sexual Behaviour among Female In-School Adolescents Delta State, Nigeria. European Scientific Journal 10: 1857-7431.

8. Rai T, Pradeep A, Kandpal SD (2011) Knowledge attitude practice among adolescent regarding sexually transmitted diseases in Urban Slum. Indian Journal of Community Health 23: 26-28.

9. Samkange-Zeeb FN, Spallek L, Zeeb H (2011) Awareness and Knowledge of Sexually Transmitted Diseases (STDs) Among School-going Adolescents in Europe: A Systematic Review of Published Literature. BMC Public Health 11: 727 .

10. Mudassir AS, Azhar SS, Keivan A, Tahir MK (2010) Awareness of Schoo Students on Sexually Transmitted Infections (STIs) and their Sexual Behavior: A Cross-sectional Study Conducted in Pulau Pinang, Malaysia. BMC Public Health 10: 47.

11. Amu EO, Adegun PT (2015) Awareness and Knowledge of Sexually Transmitted Infections among Secondary School Adolescents in Ado Ekiti, South Western Nigeria. Journal of Sexually Transmitted Diseases, p: 7

12. Basim MA (2014) Knowledge and Awareness of Sexually Transmitted Diseases Among Male University Students in Taif, Saudi Arabia. International Journal of Medical Science and Public Health 3: 342-348.

13. Dangui Z, Hui P, Binglin C, Frieda L, Jeremy F, et al. (2013) Sexual behaviors and awareness of sexually transmitted infections among Chinese university students. J Infect Dev Countries 12: 966-974.

14. Florence SZ (2013) Assessing knowledge and awareness of sexually transmitted infections among school-going adolescents. Dissertation for the academic grade of Doctor Public Health, University of Bremen, Faculty of Human and Health Sciences.

15. Hafsat R, Franklin N, Muhabbad M, Zakar F (2007) Knowledge and Belief of adolescents regarding sexually transmitted infections and HIVIAIDs in a rura district in Pakistan. Journal of Pakistan Medical Association 57: 8-11.

16. Nigeria Demographic and Health Survey (2013) Preliminary Report Abuja: National Population Commission and ICF International. Nigeria: What Role for Governments? African Journal of Reproductive Health 8: 546-554.

17. Andersson E, Milson I (2002) Knowledge about the Prevention of sexually transmitted diseases, a longitudinal study of young women from 16-23 years of age. Sex Transm Infect 78: 339-341. 